\title{
Overview of low emission combustors of aircraft turbine drive units
}

It is important to notice that aircraft turbine drive units are commonly used in the modern aviation. The piston engines are often reserved for small and/or sportive aircraft. The turbine drive units are also combustion engine. This paper presents the most popular combustors used in the aeronautical turbine engines. Firstly there are listed the requirements that a combustor has to achieve. Then are presented the combustor designs that permit to achieve the firstly presented requirements. In this work are presented the LPP, TAPS, $R Q L$, graduated combustion zone, VGC, exhaust recirculation system combustors. For each combustor design is enlighten its principle of work, described the etymology of the given name to this design and shown a scheme. The work is closed by a briefly conclusion about the described combustor.

Key words: aircraft, engine, low emission, combustors, design

\section{Introduction}

Combustors are inseparable elements of turbine drive units. Their task is to transfer the energy contained in the fuel into the air stream flowing through the turbine engine. Improvement of the design of combustor can be done taking in consideration different criterion. The first of the criteria is to optimize the combustion process to improve the combustor efficiency. The second direction of improvement the combustors is to reduce the emissions. In order to perform the above-mentioned steps, a variety of engineering tools have been created to enable faster and simpler pre-verification of the modifications. Such tools include computer programs that enable simulation of mechanical loads, thermal loads and combustion processes. The use of these tools leads to minimization of manufactured and tested prototypes, saving time and financial resources, from where the ever-increasing effectiveness of the combustion chamber designing process.

The first criteria, that can be considered during designing turbine engine, is to increase the efficiency of combustor. When fuel is burned, a part of the fuel will not be consumed or will not be oxidized to the most stable chemical form. In most cases, this is simply due to imperfections of the air-fuel mixture, and in particular when the entire fuel is not well evaporated or when the mixture is not homogeneous in its entire volume. In order to prevent these adverse phenomena, design solutions of combustors have been developed such as: increasing the number of fuel injectors (which permits better fragmentation of the fuel), the use of developed methods to turbulence the air entering into the combustor liner and heating fuel before entering into the injectors using hot oil from the engine lubrication system.

The second criteria for the design of turbine drive units is to reduce atmospheric emissions. One of the more harmful substances emitted by this type of engine are nitrogen oxides $\left(\mathrm{NO}_{\mathrm{x}}\right)$. This substance is responsible for numerous respiratory health problems, acid rains and destruction of the ozone layer [1]. This substance is naturally produced by combustion as a result of excessive combustion temperature. Its formation is largest when fuel is burned in stoichiometric proportions (Fig. 1 and Fig. 2). In order to avoid combustion in the stoichiometric proportion, lean or rich combustion may be designed. The combustion of a rich mixture promotes the reduction of nitrogen oxide $\left(\mathrm{NO}_{\mathrm{x}}\right)$ emissions, but also results in higher carbon monoxide (CO) and hydrocarbons (HC) emissions. The combustion of a lean air-fuel mixture, in addition to reduce nitrogen oxide emissions $\left(\mathrm{NO}_{\mathrm{x}}\right)$, also reduces carbon monoxide (CO) emissions, but leads to an increase in hydrocarbons emissions (HC). It is the way of designing the combustion process that permits the combustion of fuel outside the stoichiometric ratio; these solutions reduce nitrogen oxide $\left(\mathrm{NO}_{\mathrm{x}}\right)$ emissions.

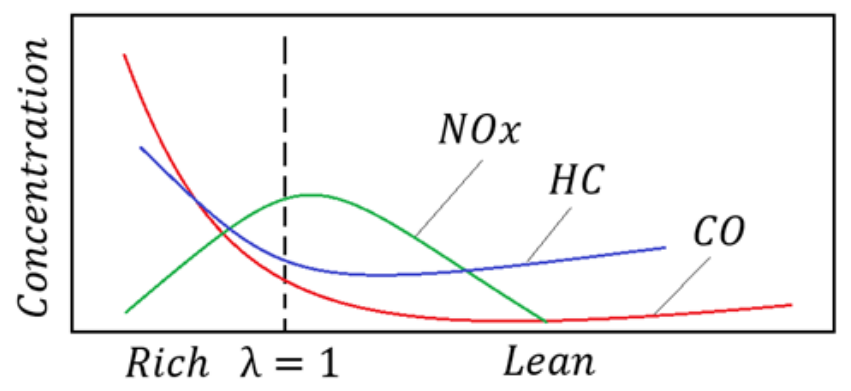

Fig. 1. Example of the effect of the air variation delivered to the combustion zone on the formation of nitrogen oxides $\left(\mathrm{NO}_{\mathrm{x}}\right)$ and other atmospheric pollutants (on the example of the petrol combustion) (basing on [2])

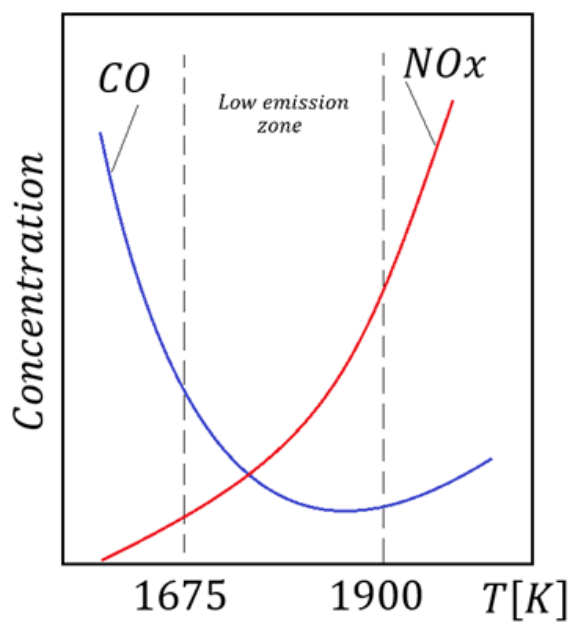

Fig. 2. Effect of combustion temperature on nitrogen oxide formation (basing on [3]) 


\section{Development direction of combustors in aircraft turbine engines}

\subsection{Optimization of the air-fuel mixture formation process}

Combustors permit fuel energy transmission into the air stream flowing through the combustor. Depending on the degree of heating of the air in the combustor and the intensity of the air mass stream, a certain amount of fuel should be brought into the combustor. The same amount of fuel may be brought in different ways. It is important to note that, in order to create a air-fuel mixture with optimal parameters, it is necessary to ensure the best possible fuel spray and adequate turbulence of the forming mixture. The smaller is the size of the fuel droplets, the larger evaporation surface area is obtained, which permits for more intense reception of heat from the environment (from the air arriving behind the compressor, and from the combustion zone), and consequently leads to faster evaporation of the fuel. Properly evaporated fuel is not able to ensure the homogeneity of the air-fuel mixture. In order to ensure its homogeneity, swirled air must be delivered into the air-fuel mixture formation zone. Faster evaporation of fuel and uniformity of its distribution in the air stream, provide conditions for the lower temperature fluctuations in the combustion zone, which leads to a reduction in nitrogen oxide emissions $\left(\mathrm{NO}_{\mathrm{x}}\right)$, and permits more complete combustion of the fuel, which permits a reduction in hydrocarbon $(\mathrm{HC})$ and carbon monoxide (CO) emissions.

Fuel systems with more injectors may be used to ensure that the fuel evaporation processes are carried out and that the fuel is properly mixed with air, while maintaining an adequate fuel mass flow. In that system, each injector delivers less fuel, but with a higher degree of spraying. The work performed in Russia, presented by A.N. Markushin, A.V. Baklanov, and N.E. Tsyganov, indicates through experimental studies that the use of higher number of injectors makes possible to significantly reduce emissions of substances such as nitrogen oxides $\left(\mathrm{NO}_{\mathrm{x}}\right)$ and carbon monoxide (CO) [4].

The temperature of the fuel supplied to the injector also affects the evaporation process of the fuel during the airfuel mixture formation. Higher the fuel temperature at the injector's inlet is, lower amount of heat will be needed to evaporate the fuel outing from the injector. However, the evaporation temperature cannot be excessive in order to avoid the formation of fuel vapor "jams" in the fueling system. Fuel-oil heat exchangers are used to increase the fuel temperature arriving into the injector [5]. It permits the desired fuel temperature to be incurred before arriving into the injector, while cooling the oil from the lubrication system, which also partially permits the cooling of the sensitive drive unit zones (the bearing of the turbine shaft(s), gearbox components, etc.).

\subsection{Stoichiometric combustion avoiding in the combustors}

As it has already been shown, it is possible to reduce the emission of substances harmful for humans and the environment by avoiding the stoichiometric combustion of the air-fuel mixture. Avoiding stoichiometric combustion re- duces the combustion temperature, resulting in lower nitrogen oxide $\left(\mathrm{NO}_{\mathrm{x}}\right)$ emissions. There are therefore two fundamental ways to approach this problem. The first is the combustion of a lean air-fuel mixture, in which there is an excess of air compared to the theoretical air demand. This solution includes combustors such as LPP and TAPS. The second method is to burn a rich air-fuel mixture. For this solution, the RQL combustors may be assigned. There are also other solutions, combining the combustion of a rich and lean air-fuel mixture. In the latter category of technical solutions, variable geometry combustion chambers and graduated combustion zone combustors may be cited.

LPP combustors (lean premixed prevaporized) - LPP combustors adopt maximum evaporation of the fuel and its mixing with air, the quantity of which is greater than the theoretical demand. It is therefore possible to talk about the "Lean" combustor referring to the lean air-fuel mixture, "Premixed" for optimal mixing of fuel with air, and "Prevaporized" in reference to the rapid evaporation of fuel, from where comes the name of the LPP combustors (Lean Premixed Prevaporized). Burning a lean air-fuel mixture will reduce the combustion temperature, which in turn will reduce emissions of nitrogen oxides $\left(\mathrm{NO}_{\mathrm{x}}\right)$. The LPP combustion chamber consists of three zones. The first zone is responsible for spraying fuel in the air stream, for evaporation of fuel and thus for the formation a lean air-fuel mixture. The second combustor zone is the place where the previously prepared air-fuel mixture is burned; the combustion zone is stabilized by a recirculation zone. The last combustor zone is the exhaust-air mixing and cooling zone. It can be concluded that throughout the combustion process in the combustor, the fuel-air mixture created and burned is in a lean state, which has a lower combustion temperature as a consequence, which permits to reduce the emissivity of the these combustors [6]. The LPP combustors must be adequately shaped to form a stable recirculation zone. This is very important because the combustion of a lean air-fuel mixture is generally unstable. The diagram of the LPP combustion chamber is shown in Fig. 3, on which the airfuel mixture formation zone can be seen in particular.

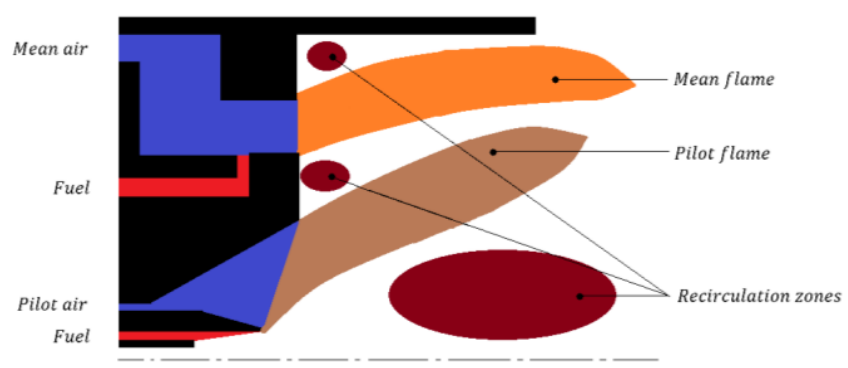

Fig. 3. LPP combustor scheme (basing on [7])

TAPS combustors (twin annular premixing swirler) another combustor, which is also in the category of the combustors with lean air-fuel mixtures, are the TAPS combustors. This combustor has two air swirls, to which fuel is also delivered. The administered fuel, and the air from the central (internal) swirl, permits the formation of a rich airfuel mixture. This is the combustion process that can be found in classical combustors. The presence of this central 
rich combustion zone permits to generate a pilot flame, permitting partial stabilization of the remaining, lean, combustion zone. Part of the air from the central swirl and the air from the outer swirl permits an optimal mixing of air and fuel spray arriving from between the swirls, forming a lean fuel-air mixture. The combustion of a lean air-fuel mixture is not generally stable. In this type of combustor, the main, lean, combustion zone is stabilized by the centrally located pilot flame, and by the formation of recirculation zones. Thus, it is called a "Twin Annular Swirler" combustor, referring to the fact that the combustor contains a double ring (swirlers) permitting the "Premixing" of the fuel with air. On the low load of the turbine drive unit, fuel is fed only to the central system, which permit the formation of a rich pilot flame, ensuring the running of the turbine engine. As the engine power increases, the fuel begins to be fed into the perimeter combustion zone, where lean combustion takes place. At the same time, recirculation zones are being established, which are increasingly beginning to stabilize the lean combustion zone. After exceeding a certain power value of the engine, the recirculation zones are so significant that they are able to fully stabilize the lean combustion zone; the pilot flame is extinguished. The suppression of the pilot flame reduces hydrocarbon $(\mathrm{HC})$ and carbon monoxide (CO) emissions. Compared to the LPP combustion chamber, the TAPS combustion chamber is characterized by greater flame stabilization safety by using a pilot flame on the low load of the drive unit. In addition, the combustion chamber is characterized by very low emissions of nitrogen oxides $\left(\mathrm{NO}_{\mathrm{x}}\right)$; the third generation of TAPS combustors has reduced around $75 \%$ of nitrogen oxide $\left(\mathrm{NO}_{\mathrm{x}}\right)$ emissions planned in the CAEP/6 [6]. Figure 4 shows the work principle of the TAPS combustor.

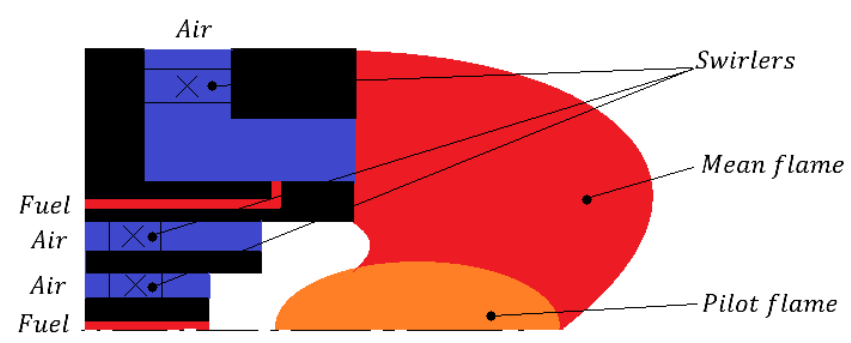

Fig. 4. TAPS combustor scheme (basing on [8])

RQL combustors (rich-burn, quick-mix, lean-burn) another type of combustors is a combustor containing two combustion zones; the first with a rich air-fuel mixture and the second with a lean air-fuel mixture. The first part of the combustor includes the injection of fuels and air swirl. The amount of air supplied into the air-fuel mixture formation and combustion zone is less than under stoichiometric conditions. Due to the combustion of the rich mixture, the combustion temperature is lower than for stoichiometric conditions, which limits the amount of nitrogen oxide $\left(\mathrm{NO}_{\mathrm{x}}\right)$ emissions. As a result of rich combustion, unfortunately, hydrocarbons ( $\mathrm{HC}$ ) and carbon monoxide $(\mathrm{CO})$ are created. As a result of the presence in this combustion zone of an increased amount of radicals, the flame is relatively stable. Due to the presence of this first part of the combustor, the beginning of the combustor name is "Rich-Burn". In order to burn hydrocarbons (HC) and carbon monoxide (CO), while avoiding the transition to stoichiometric combustion, a significant amount of air is supplied behind the rich combustion zone. This rapid transition into the lean combustion process will minimize the stoichiometric combustion area; because of that comes the second part of the combustor name: "Quick-Mix". The mutation of the combustion process from rich into lean will, in addition to maintaining low levels of nitrogen oxide formation $\left(\mathrm{NO}_{\mathrm{x}}\right)$, permit the achievement of hydrocarbon (HC) and carbon monoxide $(\mathrm{CO})$ combustion. In reference to this last combustion zone, comes the last part of this combustor name: "Lean-Burn". Given the structure and principle of work, its name "Rich-Burn, Quick-Mix, Lean-Burn" (RQL) can be justified. The result of this combustion process design is the reduced nitrogen oxide emissions (NOx) [6]. Figure 5 shows the scheme of the described combustor.

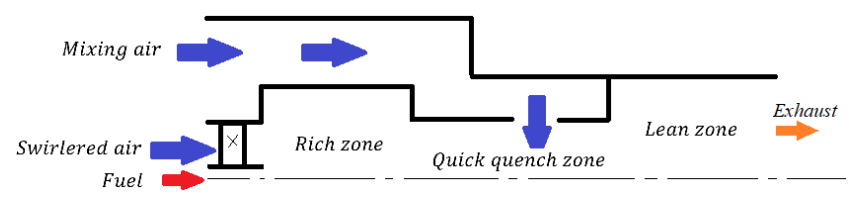

Fig. 5. RQL combustor scheme (basing on [9])

Combustors with graduated combustion zone - another combustor reducing atmospheric emissions is combustor with a graduated combustion zone. The work principle of this kind of combustor is similar to the RQL combustor, with the difference that the fuel is delivered into both combustion zones; into the rich and lean combustion zones. Air coming from the lean combustion zone quickly dissolve the rich combustion zone. The rich combustion zone permits to stabilize the combustion process of the lean combustion zone, but produces hydrocarbons (HC) and carbon monoxide (CO). In turn, the lean combustion zone permits the elimination of hydrocarbons (HC) and carbon monoxide (CO) coming from the rich combustion zone. The combustor is designed in the way that the combustion process is either rich or lean, in order to reduce the stoichiometric combustion zone, which causes a higher combustion temperature and therefore greater emissions of nitrogen oxides $\left(\mathrm{NO}_{\mathrm{x}}\right)$ [6]. Figure 6 shows the combustor analyzed above.

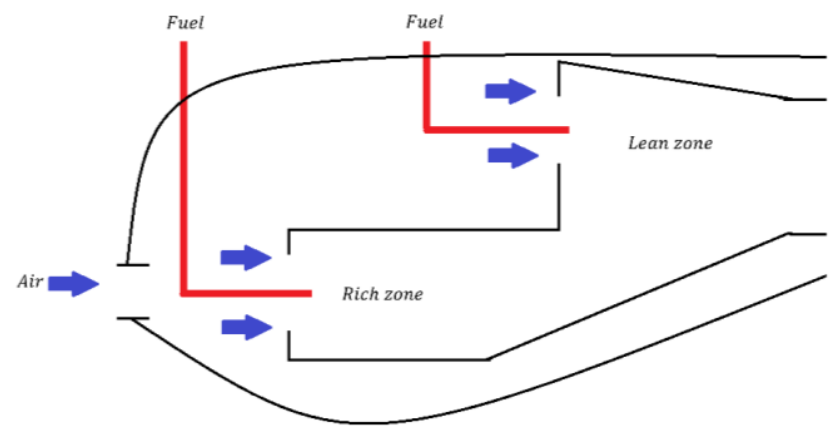

Fig. 6. Combustor with graduated combustion zone (basing on [10]) 
VGC combustors (variable geometry combustors) - as a result of the operation of the turbine drive unit at different ranges, the parameters of the air mass flowing through the combustion chamber also change. As a result of the air mass flux parameters change, a modification of the combustion process may happen and as for example a close-up to the stoichiometric combustion may occur. In order to prevent this phenomenon, it is possible to control the fuel system, but there is also the possibility of using combustors equipped with variable geometry liner. The change in the geometry of the liner consists primarily in the modification of the arrangement and the cross-sectional field of the airsupply holes, permitting to deliver air into the combustion zone. An actuator is placed outside the combustor to change the geometry of the liner. The actuator is controlled by a system that takes into account the operating range of the drive unit. The name of this combustor, "Variable Geometry Combustors" (VGC), is derived from the liner design [11]. Figure 7 shows the combustor discussed above.

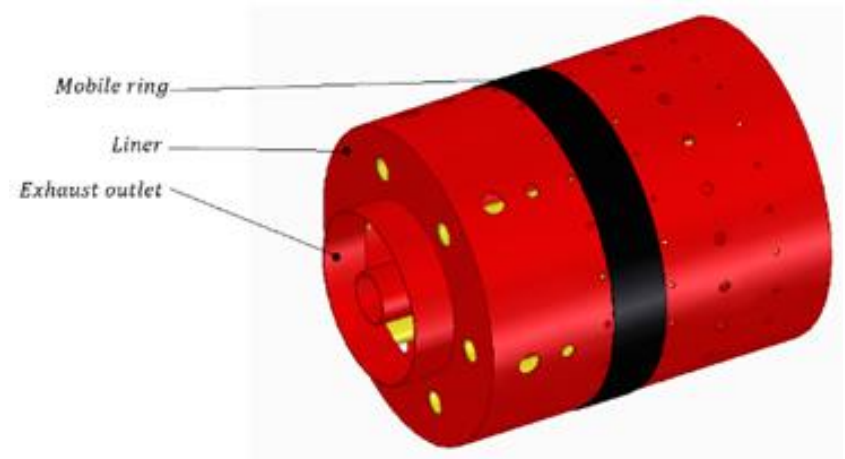

Fig. 7. VGC combustor scheme

Combustors with exhaust recirculation system - exhaust recirculation systems are today commonly used in car industry. Despite the apparent reservation of this technology for piston engines, it may be also used for aircraft turbine drive units. Exhaust gases would be collected in the combustor exhaust system, cooled, compressed to the appropriate pressure, and re-administered to the combustor. It could provoke the dilution of the air supplied to the combustion zone which in turn would reduce the peak combustion temperature. A lower combustion peak temperature would reduce the formation of nitrogen oxides $\left(\mathrm{NO}_{\mathrm{x}}\right)$. This technical solution is not used in aircraft industry, but just described. Research into this solution could assess the useful- ness of this technical solution. Figure 8 shows a combustor equipped with a exhaust recirculation system.

\section{Conclusion}

Since the creation of turbine drive units, engineers and scientists are constantly striving to improve them. In general, the turbine engines consist of an inlet, compressor, combustor, turbine and outlet system. Each of these components is of great importance for the proper and efficient work of turbine drive units. Combustors are designed in the way to improve the process of creating an air-fuel mixture and to improve the combustion process itself. These two directions of combustors development permit the reduction of atmospheric emissions and higher efficiency of these machinery. Striving for the reduction of the turbines' emissions, the use of catalytic combustors may be also interesting. The catalytic combustor permits for a flame-free fuel oxidation, which permits for a significant reduction in emissions of harmful substances into the environment. Regardless of the progress and development of the combustors, the use of the newest technologies for their development and testing was, is and will remain the standard. Increasingly improved numerical technologies permits for a better understanding of intra-combustor phenomena. Numerical technologies are intensively developed and applied to the science and technology.

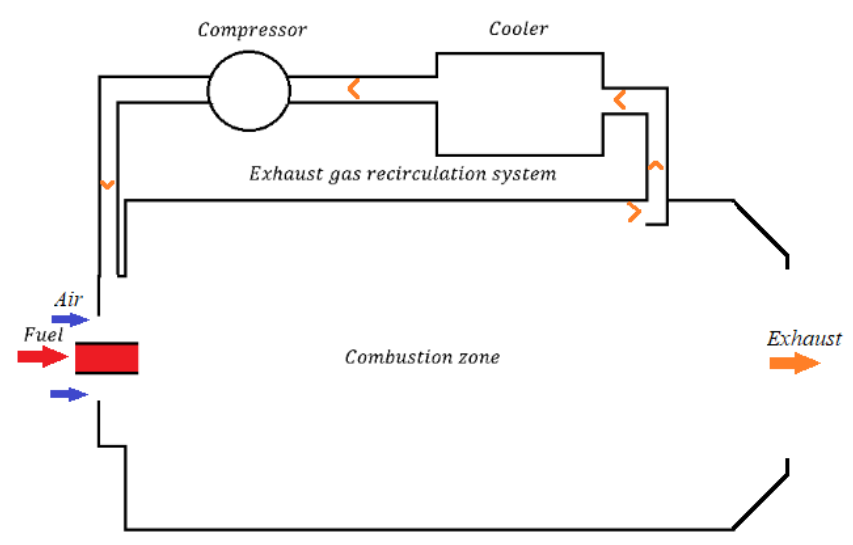

Fig. 8. Combustor with exhaust recirculation system (basing on [11])

\section{Acknowledgements}

This work is presented in order to compile contemporary designs of aircraft turbine engine combustors, linked to the reduction of their emissivity.

RQL rich-burn, quick-mix, lean-burn

TAPS twin annular premixing swirler

VGC variable geometry combustors

\section{Bibliography}

[1] Les oxydes d'azote - Polluant atmosphérique surveillé en Nouvelle-Calédonie: origines, impacts et surveillance. New Caledonia, Printer SCAL'AIR, 2015.
[2] OCDE. Études de l'OCDE sur l'innovation environnementale - Invention et transfert de technologies environnementales. 2012. Printer OCDE, Paris. https://doi.org/10.1787/20743505 
[3] GŁOWACKI, P., SZCZECIŃSKI, S. Turbinowy silnik odrzutowy jako źródło zagrożeń ekologicznych. Prace Instytutu Lotnictwa. 2011, 4(213), 252-257.

[4] MARKUSHIN, A., BAKLANOV, A., TSYGANOV, N. Improvement of aircraft GTE emission characteristics by using the microflame fuel combustion in a shortened combustion chamber. Russian Aeronautics (Iz VUZ). 2014, 56(4), 59-62.

[5] Royce Rolls. The jet engine. Derby, 1986. Printer Royce Rolls plc.

[6] GUELlOUH, N., SZAMOSI, Z., SIMENFALVI, Z. Combustors with low emission levels for aero gas turbine engines. International Journal of Engineering and Management Sciences. 2019, 4(1), 503-514. https://doi.org/10.21791/IJEMS.2019.1.62.

[7] TEMME, J.E., ALLISON, P.M., DRISCOLL, J.F. Low frequency combustion instabilities imaged in a gas turbine combustor flame tube. 50th AIAA Aerospace Sciences Meeting including the New Horizons Forum and Aerospace Exposition. 2012, Nashville, Tennessee.

[8] HERBON, J., AICHOLTZ, J., HSIEH, S.Y. et al. N+2 Advanced low $\mathrm{NO}_{\mathrm{x}}$ combustor technology - Final Report. 2017NASA/CR-2017-219410, E-19298, GRC-E-DAATN35615.

[9] KHOSRAVY EL_HOSSAINI, M. Review of the new combustion technologies in modern gas turbines. In: BENINI, E. Progress in gas turbine performance. Printer IntechOpen, London 2013, 145-164. https://doi.org/10.5772/54403

[10] BAUdOIN, C., COMMARET, P., LE LETTY, E. et al. Canadian patent no 2398 669. 2002, Canadian Intellectual Property Office.

[11] GIERAS, M. Miniaturowe silniki turboodrzutowe. Oficyna Wydawnictwa Politechniki Warszawskiej. Warszawa 2016.
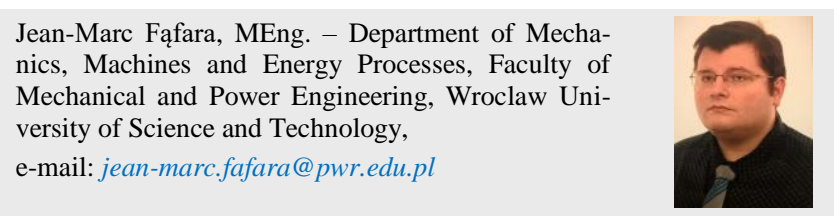